\title{
GENE EXPRESSION PROFILEOF CORPUS LUTEUMDURING DIFFERENT PHASES OF DEVELOPMENT IN EGYPTIAN BUFFALOES (Bubalus bubalis)
}

\author{
Nasser Ghanem ${ }^{1}$, Marwa S. Faheem ${ }^{1,2}$ and Sherif M. Dessouki ${ }^{1,2}$ \\ 1- Department of Animal Production, Faculty of Agriculture, Cairo University, Giza, Egypt, 2- Cairo University \\ Research Park (CURP), Faculty of Agriculture, Cairo University, Giza, Egypt
}

The current study was designed to investigate the expression profile of selected candidate genes in corpus luteum of cyclic Egyptian buffaloes. Ovaries were collected from 18 cyclic females slaughtered in Egyptian local a battoir. Corpus luteum stages of development (growth: around days 3-5, static: around days 7-10 and regression: around days 19-21 of estrous cycle) were determined by morphological features and based on our previous studiesd one in this species. Quantitative realtime polymerase chain reaction (PCR) was performed to profile the transcript abundance of genes involved in mitochondrial activity (SOD2, TFAM and CPT2), lipid metabolism (SREBP1), proinflammatory cytokine (TNFa), oxidative stress (NFE2L2), while GAPDH was used as housekeeping gene. The relative gene expression profiles of TFAM and SOD2 were up-regulated significantly $(\mathrm{P} \leq 0.05)$ in static compared to both growing and regressed phases. Meanwhile, the transcript abundance of both CPT2 and SREBP1 was significantly high at static phase and showed a minimum level of expression during regression phase of development. The expression profile of NFE2L2 revealed in significant differences among all stages of corpus luteum development. On the other hand, relative transcript abundance of TNF $\alpha$ was higher at regression phase than growth and static stages. Taken together, the pattern of mitochondrial activity and metabolism regulating genes were in correspondence with the functional and biological developmental changes of corpus luteum during estrus cycle in buffalo, being up-regulated during the growth phase, reached plateau in static phase, and finally the expression was declined during regression phase. Meanwhile, the transcript abundance of pro-inflammatory cytokine gene denoteda $\mathrm{n}$ opposite trend. Thus, gene expression profile could be used as an effective biological indicator for the cyclic changes of buffalo's corpus luteum development.

Keywords: corpus luteum, gene expression, mitochondrial activity, buffalo 